\title{
Multisensory and closed kinetic chain exercises on the functional capacity and balance in elderly women: blinded randomized clinical trial
}

\author{
Exercícios multissensoriais e de cadeia cinética \\ fechada sobre a capacidade funcional e o equilibrio \\ em idosas: ensaio clínico randomizado cego
}

Luiz Gustavo Padovini Ferreira, Caio Vitor dos Santos Genebra, Nicoly Machado Maciel, Eduardo Aguilar Arca, Alexandre Fiorelli, Alberto De Vitta*

Universidade do Sagrado Coração (USC), Bauru, SP, Brazil

\begin{abstract}
Introduction: The aging process causes losses that lead to decreased balance, gait speed and functional capacity and, therefore, there is a need of specific protocols to work preventively these variables, which will contribute to the decrease in the frequency of falls in this population. Objective: Verify the effect of a program of multisensory and closed kinetic chain exercises on the functional capacity and balance in elderly women. Methods: Randomized clinical trial masked (blind). Subjects were 32 elderly women from the Centro de Convivência of the Bauru Department of Social Welfare (Secretaria de Bem-Estar Social de Bauru) distributed in two groups: control (CG = 15) and experimental (EG = 17). Interventions: The program of multisensory and closed kinetic chain exercises was applied during an hour, once a week, for 12 weeks. Main measures: Functional capacity was measured by Timed Up and Go (TUG) and the 10-meter walking test (TC10) and their balance by the Berg Balance Scale (BBS). Results: Regarding the comparison between
\end{abstract}

\footnotetext{
LGPF: BS, e-mail: luiz.gustavopf@gmail.com

CVSG: Master's student: caio.vitor92@yahoo.com.br NMM: MS, e-mail: ni-maciel@hotmail.com

EAA: PhD, e-mail: eduardo.arca@usc.b

AF: PhD, e-mail: afiorelli@lpnet.com.br

AV: PhD, e-mail: albvitta@gmail.com
} 
the moments M1 and M2 of the EG after the intervention, there was a statistically significant increase in the functional capability $(p=0.00006)$, walking speed $(p=0.0008)$ and balance $(p=0.0006)$. Conclusion: The multisensory and closed kinetic chain-training program indicated a beneficial effect in the improvement of the elderly women balance and functional performance.

Keywords: Exercise. Health of the Elderly. Postural Balance. Accidental Falls.

\section{Resumo}

Introdução: O processo de envelhecimento provoca perdas que levam à diminuição do equilíbrio, da velocidade da marcha e capacidade funcional e, portanto, há necessidade de protocolos específicos para trabalhar preventivamente essas variáveis, que contribuirão para a diminuição na freqüência de quedas nesta população. objetivo: verificar o efeito de um programa de exercícios multissensoriais e de cadeia cinética fechada sobre a capacidade funcional e o equilíbrio em idosas. Métodos: Tratou-se de um ensaio clínico randomizado mascarado (cego). Participaram 32 idosas de Centro de Convivência da Secretaria de Bem-estar social de Bauru, distribuídas em dois grupos: controle $(G C=n 15)$ e experimental $(G E=17)$ avaliadas em dois momentos: inicial (M1 = antes da intervenção) e final (M2 = após intervenção), por meio da capacidade funcional (Timed Up and Go - TUG e velocidade de marcha - TC10) e o equilíbrio pela Escala de Equilíbrio de Berg (EEB). $O$ programa de exercícios multissensoriais e de cadeia cinética fechada foi aplicado uma vez por semana, por uma hora, durante 10 semanas. Resultados: Em relação à comparação entre os momentos M1 e M2 do GE após a intervenção, houve um aumento significativo da capacidade funcional $(p=0,00006)$, velocidade da marcha $(p=0,0008)$ e do equilíbrio $(p=0,0006)$. Conclusão: 0 programa de treinamento multissensorial e de cadeia cinética fechada sinalizou efeito favorável na melhora do equilíbrio e do desempenho funcional de idosas.

Palavras-chave: Exercício. Saúde do Idoso. Equilíbrio Postural. Acidentes por Quedas.

\section{List of abbreviations:}

BBS (Berg Balance Scale), TUG (Timed Up and Go), TC10 (the 10-meter walking test), MMSE (Mini Mental State Examination), OKC (Opened kinetic chain exercise) CKC (Closed kinetic chain exercise)

\section{Introduction}

The increase in the elderly population is a universal phenomenon that causes changes in the age pyramid. Evidences from 2000 show that $5.85 \%$ of the Brazilian population was over the age of 65 , conferring Brazil the seventh position in the list of the most aged population in the world - and Brazil is expected to occupy the sixth position in 2025 [1]. Associated with this demographic change, there is an increase in morbidities, occurring morphological, functional, biochemical and psychological changes, which result in the reduction of organs and systems functional reserves. These modifications, associated with chronic diseases, use of medicines and sedentary lifestyle increase the inability in the elderly $[2,3]$.

With the increase in the population life expectancy and the high financial costs of treating diseases that are prevalent in the old age, the interventions targeted at the elderly must be focused on the preventive aspects, not to healing ones. Among these prophylactic interventions, those related to balance maintenance and prevention of falls through physical exercises stand out, pointed to by some studies [4 - 6].

Balance exercises and closed kinetic chain protect postural stability, controlling the musculoskeletal system against gravity at rest and in motion, in addition to increasing the co-contraction of the muscles and eccentric contraction, reducing the shear strength and compressive forces adding to the joints, thereby enhancing the joint stability. Such benefits increase the ability of older people self-confidence, improve their functional capacities, and consequently their mobility for performance on tasks of daily life $[7,8]$. 
Several studies have investigated the effects of muscle strengthening using opened kinetic chain (OKC) and closed kinetic chain (CKC) exercise programs [7-10], but few studies have examined the effects of a circuit of multisensorial exercises associated with the closed kinetic chain about the balance and functional performance in older adults in the community, were still little studied [8 - 11].

Thus, the purpose of this study was to verify the effect of a program of multi-sensorial and closed kinetic chain exercises on the functional capability and balance in elderly women.

\section{Methods}

It is a randomized controlled clinical trial under blind conditions, conducted with elderly women in the city of Bauru. All participants signed a consent form before starting the study and the project was approved by the Research Ethics Committee of the Universidade Sagrado Coração, Bauru, SP, assent number 382/293, and approved by the Brazilian Clinical Trials Registry under number RBR - 9qdbh4.

The study included all women over 60 years old that agreed to participate and understood verbal commands. The exclusion criteria were elderly women that had previously underwent orthopedic surgery of the lower limbs and / or had a fracture history; ambulation disability, presence of neurological diseases affecting the musculoskeletal system, acute inflammatory process of the musculoskeletal system and neoplasia in the past five years, and those who used medication with a broad action in the immune system. We also excluded the women who performed regular physical exercises twice a week or more, as well as those who presented conditions suggestive of cognitive changes detectable by the Mini Mental State Examination (MMSE), according to the level of education [12].

All elderly women underwent the evaluation of the balance analysis in daily tasks and the evaluation of the functional performance, in two moments: initial (M1 = before intervention) and final (M2 = after intervention).

After the initial evaluation, which ensured the inclusion and exclusion criteria, the elderly were placed, through drawing, to the experimental (EG) and control groups (CG). The researcher responsible for the intervention had no knowledge of the evaluations carried out. The evaluators had no knowledge of which group the volunteer belonged. The attendance of the elderly women was controlled and those with more than two absences were excluded from the data analyses.

The sample consisted of 32 elderly women from the Centro de Convivência of the Department of Social Welfare in Bauru - SP. The CG was composed of 15 and the EG was composed of 17 women.

\section{Measures and instruments}

The outcomes were balance and functional performance. The balance was evaluated by the Berg Balance Scale (BBS), which consists of fourteen daily tasks scored from 0 to 4 , for a total of 56 points, in which an index equal to or below 36 is associated with $100 \%$ risk of falls. The scale has a good interrater reliability (0.96) and test-retest reliability (TRR $=0.98)$, in addition to a moderate to high correlation with other instruments of functional evaluation of the balance [13].

The functional performance was evaluated by using the Timed Up and Go -TUG [14, 15] and the 10-meter walking test -TC10 [16].

The TUG consists in performing the task of rising (without support) from a $45 \mathrm{~cm}$-high standard arm chair (having as reference the height from the floor), walk 3 meters, turn, walk back to the chair and sit down $[14,15]$. The evaluators measured the execution time of the test. The test-retest reliability was reported as good $(r=0.93)$ and the inter-rater reliability was of IRR $=0.9921$. For the TC10, the volunteers were asked to walk at their normal walking speed through a 10-meter flat path. The first two meters for acceleration and the final two for the slowdown were disregarded [16]. This test is the best predictor of falls and functional dependence in the elderly; the normal speed is used, in other words, comfortable, to verify functional limitations in everyday life, such as the ability to cross a street [16].

\section{Intervention protocol}

The intervention program was carried out over a period of twelve weeks, once a week, with duration of an hour a day. The program consisted of four stages: warm-up, multi-sensory and closed kinetic chain exercises, and slowdown. 
The warm-up stage was comprised of walks with acceleration and deceleration, forward, backward and to the sides. This stage lasted 10 minutes.

The multi-sensory exercises were developed in the form of a training circuit consisting of autonomous and complementary units, called stations [17].

The circuit was composed of thirteen stations: "A": Lateral steps to the right and left sides; "B": Unipodal support exercise (right and left); “C": Back sensitive walking (with the support only of heels); "D": Walking backwards, with total feet support, "E": "Hit the target", backwards, with the balls connected by lines in the sides; "F": Walking on an unstable surface (mattress); "G": Walking with the support of only the anterior third of the back of the feet; " $H$ ": Walking forward, with the legs separate, with total feet support; "I": Multidirectional reach (levels of difficulty with different distances); "J": Walking forward, legs crossed, with total feet support; "L": "Ball into the basket" (levels of difficulty with different distances); "M": Walking with narrowing ground and in a circumferential route; "N": Walking straight forward and backwards. All the elderly women completed the circuit twice in a total of thirty minutes.

The exercises in closed kinetic chain were performed by semi crouch, only using the body weight, 3 sets of 12 repetitions; they are justified for being more functional, decreasing the compression force in the patellofemoral articulation and minimizing the risk of knee pain $[14,18]$.
The slowdown was performed in the last 10 minutes through relaxation and breathing techniques.

\section{Statistical analysis}

The calculus of the sample size was based on a previous pilot study, with 12 volunteers, and a confidence interval of $95 \%$, a $20 \%$ error, a 0.50 effect size, and a $\alpha$ value of 0.05 . Using the measure of the functional performance, this calculus showed the need of 13 volunteers in each group. Initially, we performed the Komolmogorov-Smirnov (KS) test to verify its Gaussian distribution. The means and standard deviation calculations were used in the descriptive statistics. The comparison of the balance and functional performance measures, preand post-intervention, inter and intra-groups, was performed using the Student's t-test at a significance level of $5 \%$.

\section{Results}

Thirty-two elderly women were included in the study, 15 elderly women in the CG and 17 elderly women in the EG. Figure 1 demonstrates the flow chart for the constitution of the groups and the clinical and demographic characteristics of each group are in Table 1.

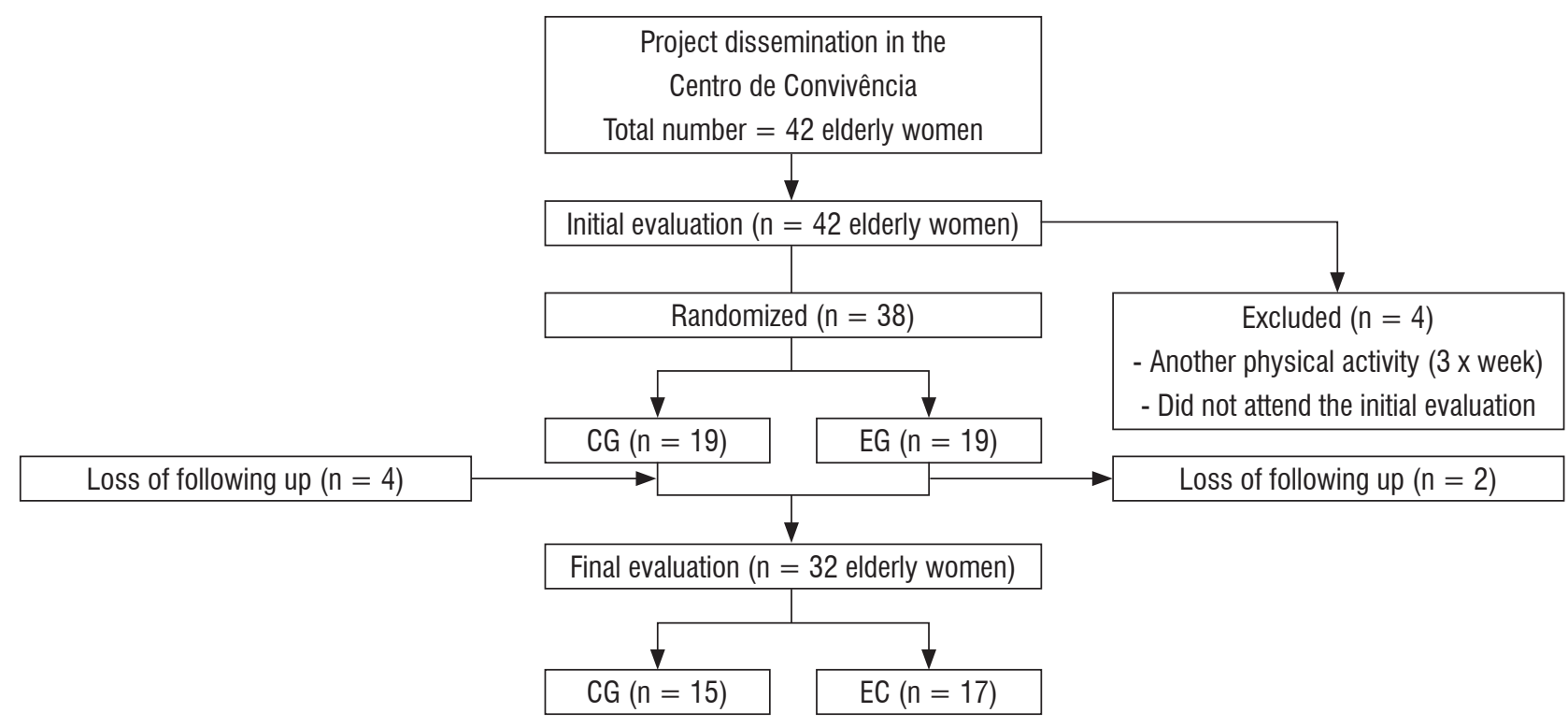

Figure 1 - Constitution of the groups. 
Table 1 - Distribution of the frequencies of individuals according to sociodemographic characteristics. Bauru (SP-Brazil), 2014

\begin{tabular}{llcc}
\hline & & CG & EG \\
\hline \multirow{2}{*}{ Age } & Years* & 69.0 & 71.0 \\
& & $( \pm 5.6)$ & $( \pm 5.2)$ \\
Education in years & 0 to 4 (n. \%) & $10(66.6)$ & $7(41.2)$ \\
& 5 to 12 (n. \%) & $5(33.4)$ & $10(58.8)$ \\
& Married (n. \%) & $4(26.7)$ & $6(35.3)$ \\
Marital status & Single (n. \%) & $1(6.7)$ & $1(5.9)$ \\
& Separated/widow (n. \%) & $10(66.7)$ & $10(58.9)$ \\
\multirow{2}{*}{ Body mass index } & $\mathrm{Kg} / \mathrm{m}^{2^{*}}$ & 25.6 & 26.9 \\
& & $( \pm 4.6)$ & $( \pm 4.8)$ \\
\hline
\end{tabular}

Note: *Values were expressed as the mean ( \pm standard deviation).

In Table 2, we observe the means and standard deviation for the Berg test in the two moments regarding the groups studied.

Regarding the comparison between M1 and M2 in the EG after the intervention, there was a statistical significant increase in the elderly balance. Comparing the groups, there was statistically significant difference in the EG compared to the CG.

Table 2 - Mean and standard deviation of the Berg test in both evaluation moments ( $\mathrm{Ml}$ and $\mathrm{M} 2$ ) regarding the groups (CG and $E G$ ) and results of statistical tests. Bauru (SP-Brazil), 2014

\begin{tabular}{lcccc}
\hline \multirow{2}{*}{ Groups } & \multicolumn{2}{c}{ Moments } & $\begin{array}{c}\text { Test } \\
\text { value }\end{array}$ & $\begin{array}{c}\text { Value } \\
\text { of } \boldsymbol{p}\end{array}$ \\
\cline { 2 - 3 } & M1 & M2 & 0.0000 & 1.0000 \\
\hline CG & $52.86 \pm 12.26$ & $52.86 \pm 2.13$ & 0.49 & \\
EG & $53.35 \pm 1.76$ & $55.64 \pm 0.49$ & $-3.4285^{\star}$ & 0.0006 \\
\hline Test value & 0.6818 & $4.5308^{\star *}$ & & \\
Value of $p$ & 0.500 & 0.000005 & & \\
\hline
\end{tabular}

In Table 3, we observe the mean and standard deviation for the TC10 test in the two evaluation moments regarding the groups studied.

Regarding the comparison between $\mathrm{M} 1$ and M2 in the EG after the intervention, there was a statistically significant increase in the functional performance of the elderly. Still in this table, there was statistically significant difference in the EG compared to the CG.
Table 3 - Mean and standard deviation of the TC10 in the two evaluation moments ( $\mathrm{Ml}$ and $\mathrm{M} 2$ ) regarding the groups (CG and EG) and results of statistical tests. Bauru (SP-Brazil), 2014

\begin{tabular}{lcccc}
\hline \multirow{2}{*}{ Groups } & \multicolumn{2}{c}{ Moments } & $\begin{array}{c}\text { Test } \\
\text { value }\end{array}$ & $\begin{array}{c}\text { Value } \\
\text { of } \boldsymbol{p}\end{array}$ \\
\cline { 2 - 3 } & $\mathrm{M} 1$ & $\mathrm{M} 2$ & 3.4150 & 0.0017 \\
$\mathrm{CG}$ & $21.61 \pm 1.576$ & $21.61 \pm 1.575$ & 3.1119 & 0.0008 \\
\hline Test value & -3.326 & -6.054 & & \\
Value of $p$ & 0.002 & 0.000001 & & \\
\hline
\end{tabular}

In Table 4, we observe the mean and standard deviation for the TUG test in the evaluation moments regarding the groups. Regarding the comparison between M1 and M2 in the EG after the intervention, there was a statistically significant increase in the functional performance. In addition, there was statistically significant difference between the EG and CG.

Table 4 - Mean and standard deviation of the TUG, in seconds, in the two evaluation moments ( $\mathrm{Ml}$ and M2) regarding the groups ( $C G$ and $E G$ ) and results of statistical tests. Bauru (SP-Brazil), 2014

\begin{tabular}{lcccc}
\hline \multirow{2}{*}{ Groups } & \multicolumn{2}{c}{ Moments } & $\begin{array}{c}\text { Test } \\
\text { value }\end{array}$ & $\begin{array}{c}\text { Value } \\
\text { of } \boldsymbol{p}\end{array}$ \\
\cline { 2 - 3 } & M1 & M2 & 0.9454 & 0.3604 \\
EG & $12.24 \pm 1.251$ & $12.12 \pm 1.358$ & 0.3639 & 0.00006 \\
\hline Test value & -4.354 & -6.705 & & \\
Value of $p$ & 0.0001 & 0.000000 & & \\
\hline
\end{tabular}

\section{Discussion}

The effect of the multisensory and closed kinetic chain exercises on the balance and functional performance in elderly women is a subject of interest for many health professionals. Answering the question investigated in this study, the experimental group showed improvement in balance, gait speed and functional capacity, after the intervention.

The results showed an increase in the balance in the EG after the intervention program with a statistical difference, corroborating with other studies [19 - 22], diverging from a study in São Paulo, where there were not noted significant differences 
between the average scale of Berg Balance between groups of men subjected to resistance training and a control subject to no-load exercises [23].

With aging, the answer of the Central Nervous System loses its refined regulation, due to the decline in the proprioceptive systems, visual and vestibular, which decreases in speed, time and synchronism the answer to the balance; therefore, it is necessary to stimulate it. Thus, the multisensory exercises provide feedback to it, trying through mechanisms of neuroplasticity to cause a relearning and record of a better answer to postural control, making the adjustments for the stability maintenance more effective, which can be seen in the improvement of the balance [24 - 26].

The elderly women of this study showed a significant increase in walking speed and functional capacity after the intervention, similar to findings from other studies [18, 19, 23, 27].

These results allow us to assume that multisensory exercises combined with the closed kinetic chain exercises are able to improve the physical function of the elderly, letting them more independent.

A positive factor that stands out is the contribution of these types of exercises in the improvement of body awareness that, consequently, reflects in the body positioning control during activities, also helping in the postural control $[7,8]$.

Another point that probably contributed to the results of this study was the closed kinetic chain exercises. These exercises generate the cocontraction of the agonist and antagonist muscles to provide a greater articular stability, they increase the proprioception; the feedback is believed to be more efficient thanks to the body compressive forces and to the contact of the foot with the ground, besides the production of functional movements of the lower limb through concentric and eccentric contractions of the muscles involved in the joint movements of the hip, knee and ankle, activity commonly performed in daily activities [28 - 30].

This study did not correlate the state of psychosocial health of the subjects analyzed, during the experiment, with the variables investigated, which represented a limitation. In addition, we cannot rule out the possibility of a type II error in the results analyses, and a limitation regarding the external validity of the study, because of reduced sample size.
A positive aspect of the study was that it excluded the elderly women who had more than two consecutive absences; this seemed to be an appropriate decision to ensure these principles and evaluate with criteria the result of the intervention effect. In addition, this paper presents a simple, efficient proposal regarding the human resources, economical regarding the material resources, as well as uniform and easily replicable, from the perspective of the continuity of the research and reproduction of the experiment.

\section{Conclusion}

According to the results, we can conclude the program of multisensory and closed kinetic chain exercises generated a significant improvement in the walking speed, functional capacity and balance in elderly women. Therefore, this type of exercise in the elderly should be encouraged and implemented in order to contribute to the improvement of their functional performance and to the decrease the risk of falling.

\section{Acknowledgments}

National Research Council (CNPq) for assistance in Scientific Initiation grant.

\section{References}

1. OMS: Promoción de la salud. Glosario. Índice de desenvolvimento humano. Programa das nações unidas para o desenvolvimento. 2010 [cited 2015 Nov 18]. Available from: https://tinyurl.com/ yck2swzv.

2. Zambaldi PA, Costa TABN, Diniz GCLM, Scalzo PL. Efeito de um treinamento de equilíbrio em um grupo de mulheres idosas da comunidade: estudo piloto de uma abordagem específica não-sistematizada e breve. Acta Fisiatr. 2007;14(1):17-24.

3. Alfieri FM, Werner A, Roschel AB, Melo FC, Santos KIS. Mobilidade funcional de idosos ativos e sedentários versus adultos sedentários. Braz J Biomotricity. 2009;3(1):89-94. 
4. Granacher U, Lacroix A, Muehlbauer T, Roettger K, Gollhofer A. Effects of core instability strength training on trunk muscle strength, spinal mobility, dynamic balance and functional mobility in older adults. Gerontology. 2013;59(2):105-13.

5. Park H, Kim KJ, Komatsu T, Park SK, Mutoh Y. Effect of combined exercise training on bone, body balance, and gait ability: a randomized controlled study in community-dwelling elderly women. J Bone Miner Metab. 2008;26(3):254-9.

6. Sherrington C, Whitney JW, Lord SR, Herbert RD, Cumming RG, Close JC. Effective exercise for the prevention of falls: a systematic review and metaanalysis. J Am Geriatr Soc. 2008;56(12):2234-43.

7. Woollacott MH, Tang PF. Balance control during walking in the older adult: research and its implication. Phys Ther 1997;77(6):646-60.

8. Balci P, Tunay VB, Baltaci G, Atay AO. The effects of two different closed kinetic chain exercises on muscle strength and proprioception in patients with patellofemoral pain syndrome. Acta Orthop Traumatol Turc. 2009;43(5):419-25.

9. Dannelly BD, Otey SC, Croy T, Harrison B, Rynders CA, Hertel JN, et al. The effectiveness of traditional and sling exercise strength training in women. J Strength Cond Res. 2011;25(2):464-71.

10. Augustsson J, Thomeé R. Ability of closed and open kinetic chain tests of muscular strength to assess functional performance. Scand J Med Sci Sports. 2000;10(3):164-8.

11. Pincivero DM, Lephart SM, Karunakara RG. Relation between open and closed kinematic chain assessment of knee strength and functional performance. Clin J Sport Med. 1997;7(1):11-6.

12. Bertolucci PHF, Brucki SMD, Campacci SR, Juliano Y. O Mini-Exame do Estado Mental em uma população geral: impacto da escolaridade. Arq Neuro-Psiquiatr. 1994;52(1):1-7.

13. Steffen TM, Hacker TA, Mollinger L. Age and genderrelate test performance in community-dwelling elderly people: six-minute walk test, berg balance scale, timed up and go test and gait speeds. Phys Ther. 2002;82(2):128-37.
14. Eyigor S, Karapolat H, Durmaz B. Effects of a groupbased exercise program on the physical performance, muscle strength and quality of life in older women. Arch Gerontol Geriatr. 2007;45(3):259-71.

15. Podsiadlo D, Richardson S. The Timed "Up \& Go": a test of basic functional mobility for frail elderly persons. J Am Geriatr Soc. 1991;39(2):142-8.

16. Shinkai S, Watanabe S, Kumagai S, Fujiwara Y, Amano $\mathrm{H}$, Yoshida $\mathrm{H}$, et al. Walking speed as a good predictor for the onset of functional dependence in a Japanese rural community population. Age Ageing. 2000;29(5):441-6.

17. Costa JN, Avelar BP, Safons MP, Gonçalves CD, Pereira MM. Efeitos do circuito de equilíbrio sobre o equilíbrio funcional e a possibilidade de quedas em idosas. Motricidade. 2012;8(Suppl 2):485-92.

18. Lustosa LP, Coelho FM, Silva JP, Pereira DS, Parentoni AN, Dias JM, et al. The effects of a muscle resistance program on the functional capacity, knee extensor muscle strength and plasma levels of IL-6 and TNFalpha in pre-frail elderly women: a randomized crossover clinical trial - a study protocol. Trials. 2010;11:82.

19. Bechara FT, Santos SMS. Efetividade de um Programa Fisioterapêutico para Treino de Equilíbrio em Idosos. SaudPesq. 2008;1(1):15-20.

20. Nascimento LCG, Patrizzi LJ, Oliveira CCES. Efeito de quatro semanas de treinamento proprioceptivo no equilíbrio postural de idosos. Fisioter Mov. 2012;25(2):325-31.

21. Leal SMO, Borges EGS, Fonseca MA, Alves Jr. ED, Cader S, Dantas EHM. Efeitos do treinamento funcional na autonomia funcional, equilíbrio e qualidade de vida de idosas. Rev Bras Ci e Mov. 2009;17(3):61-9.

22. Lopes MNSS, Passerini CG, Travensolo CF. Eficácia de um protocolo fisioterapêutico para equilíbrio em idosos institucionalizados. Semina Cienc Biol Saude. 2010;31(2):143-52.

23. Silva A, Almeida GJM, Cassilhas RC, Cohen M, Peccin MS, Tufik S, et al. Equilíbrio, Coordenação e Agilidade de Idosos Submetidos à Prática de Exercícios Físicos Resistidos. Rev Bras Med Esporte. 2008;14(2):88-93. 
24. Goulart F, Chaves CM, Chagas e Vallone MLD, Carvalho JA, Saiki KR. O movimento de passar de sentado para de pé em idoso: Implicações para o treinamento funcional. Acta Fisiatrica. 2003;10(3):138-43.

25. Freitas Jr P, Barela JA. Alterações no funcionamento do sistema de controle postural de idosos. Rev Port Cien Desp. 2006;6(1):94-105.

26. Gillespie LD, Robertson MC, Gillespie WJ, Sherrington C, Gates S, Clemson LM, et al. Interventions for preventing falls in older people living in the community. Cochrane Database Syst Rev. 2012;9:CD007146.

27. Fernandes AMBL, Ferreira JJA, Stolt LROG, Brito GEG, Clementino ACCR, Sousa NM. Efeitos da prática de exercício físico sobre o desempenho da marcha e da mobilidade funcional em idosos. Fisioter Mov 2012;25(4):821-30
28. Kwon YJ, Park SJ, Jefferson J, Kim K. The effect of open and closed kinetic chain exercises on dynamic balance ability of normal healthy adults. J Phys Ther Sci. 2013;25(6):671-4.

29. Fehr GL, Cliquet Jr A, Cacho EWA, Miranda JB. Efetividade dos exercícios em cadeia cinética aberta e cadeia cinética fechada no tratamento da síndrome da dor femoropatelar. Rev Bras Med Esporte. 2006;12(2):66-70.

30. Witvrouw E, Danneels L, Van Tiggelen D, Willems TM, Cambier D. Open versus closed kinetic chain exercises in patellofemoral pain: a 5-year prospective randomized study. Am J Sports Med. 2004;32(5):1122-30.

Received on $05 / 12 / 2016$

Recebido em 12/05/2016

Approved on 06/21/2017

Aprovado em 21/06/2017 